\title{
EVALUATION OF TEMPERATURE AND STRESS IN FIRST STAGE HIGH PRESSURE TURBINE BLADES OF A DIRECTIONALLY-SOLIDIFIED SUPERALLOY DZ125 AFTER SERVICE IN AEROENGINES
}

\author{
Y.D. Chen ${ }^{1}$, Y.R. Zheng ${ }^{1}$, C.B. Xiao ${ }^{2}$, Q. Feng ${ }^{1}$ \\ ${ }^{1}$ State Key Laboratory for Advanced Metals and Materials, University of Science and Technology Beijing, Beijing, 100083, China \\ ${ }^{2}$ Science and Technology on Advanced High Temperature Structural Materials Laboratory, Beijing Institute of Aeronautical Materials, \\ Beijing, 100095, China
}

Keywords: DZ125 superalloy, temperature, stress, microstructural degradation, quantitative characterization, rafting

\begin{abstract}
To get the actual service temperature and stress distribution of turbine blades is very important for the design and maintenance in aeroengines. However, the measurement of temperature and stress in serviced blades has always been a challenge. It is necessary to develop an evaluation method based on the microstructural degradation of turbine blades. In this study, the microstructure of three turbine blades made of DZ125 alloy, which have been serviced for different service cycles, was investigated. The dissolution and rafting extent of $\gamma^{\prime}$ precipitates were quantitatively characterized by using the volume fraction $\left(\mathrm{V}_{f}\right)$ and rafting degree $(\Omega)$, respectively. The results show that the extent of microstructural degradation varies with the service time and location of three turbine blades. The $\mathrm{V}_{f}$ values decreased gradually and $\Omega$ values raised gradually in a certain location of turbine blades with the increase of service time. According to the service simulation experiments of DZ125 superalloy, the quantitative and approximate monotonic relationship was established among temperature, stress, $\mathrm{V}_{f}$ and $\Omega$. The service temperature and stress of turbine blades have been evaluated by the above relationship. This study is helpful to understand the effect of service temperature and stress on microstructural degradation of directionally-solidified turbine blades, and probes for a new way to evaluate temperature and stress.
\end{abstract}

\section{Introduction}

Gas turbine blades in modern aeroengines are usually manufactured by using investment casting to create sophisticated internal cooling passages and shape due to their extremely hostile serviced environment. The distribution of the actual service temperature and stress is able to provide important guidance for the design of blade shape and cooling passages. In the meantime, it can also offer valid references for the preferential inspection positions when turbine blades are repaired. Unfortunately, the acquisition of working conditions in serviced blades has been always a challenge. To date, the prediction and assessment of service temperature and stress of a turbine blade mainly rely on the method of numerical simulation. However, it is difficult to accurately predict by using the simulation method because of the complicated influences of the coating and cooling systems, and the uncertainty of the boundary conditions in a turbine blade [1, 2]. Therefore, developing a quantitative evaluation method of service temperature and stress based on experimental investigation becomes more necessary.

It has been found that the microstructure of Ni-base superalloys in turbine blades will inevitably degrade after service, including the coarsening and rafting of $\gamma^{\prime}$ precipitates, the decomposition and transformation of carbides, the degeneration of grain boundaries and so on [3-6]. Among them, $\gamma^{\prime}$ precipitates are the most important strengthening phase, and their degradation extent is very sensitive to service temperature, stress and time [7-9]. Thus, a method of classifying the service conditions of Ni-base superalloy turbine blades in an aeroengine by using the degraded microstructures has recently drawn attention to researchers [10]. Miura et al. analyzed service conditions, qualitatively, according to the morphology of $\gamma^{\prime}$ precipitates in serviced turbine blades made of polycrystalline and single crystal Ni-base superalloys $[11,12]$. However until now, a quantitative evaluation method of temperature and stress distribution along the airfoil of turbine blades has not been acquired.

In this study, the service simulation experiments, including the thermal exposure without stress and thermal-mechanical coupling simulation experiments, were conducted to investigate the effect of temperature and stress on microstructural degradation. The quantitative relationship among the temperature, stress, time and $\gamma^{\prime}$ volume fraction as well as the rafting extent of $\gamma^{\prime}$ precipitates was established according to quantitative characterization. A new method of evaluating temperature and stress of turbine blades was developed based on the quantitative analyses of microstructural degradation.

\section{Experimental Procedures}

To acquire microstructural evolution of turbine blades during service, the microstructural analyses of serviced turbine blades were carried out first. Three turbine blades, made of directionally-solidified superalloy DZ125, were taken from serviced aircraft engines, which have been in service for $300 \mathrm{~h}$ (Blade 1), $600 \mathrm{~h}$ (Blade 2) and $900 \mathrm{~h}$ (Blade 3), respectively. Five cross-sections were sliced along each turbine blade, and they were named as section 1 , section 2 , section 3 , section 4 and section 5, respectively, shown in Fig. 1a. According to preliminary microstructural observation at 18 locations for each section, Leading edge, Pressure side, Suction side and Trailing edge were chosen as the typical investigated locations at each section (Fig. 1b). Meanwhile, the unserviced turbine blade was investigated as the initial microstructure, for comparison.

The service simulation experiments in the laboratory were conducted on directionally-solidified crystal bars $(\Phi 15 \mathrm{~mm} \times$ $170 \mathrm{~mm}$ ) of DZ125 superalloy by using creep tests with variable cross-section areas, as presented in Fig. 2, to simulate microstructural evolution under the thermal-mechanical coupling effect. The experimental temperature and stress ranges are from 900 to $1050{ }^{\circ} \mathrm{C}$ and from 18 to $400 \mathrm{MPa}$, respectively. The 
interrupted time of creep tests was $300 \mathrm{~h}$. In comparison, the thermal exposure experiments without stress influence have also been carried out in the range of 900 to $1100{ }^{\circ} \mathrm{C}$ and 100 to $900 \mathrm{~h}$. The detailed simulation experimental parameters are shown in Table I.

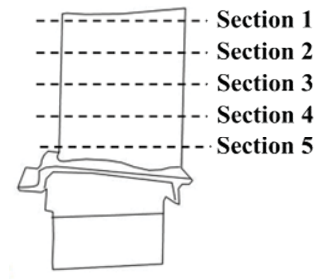

(a)

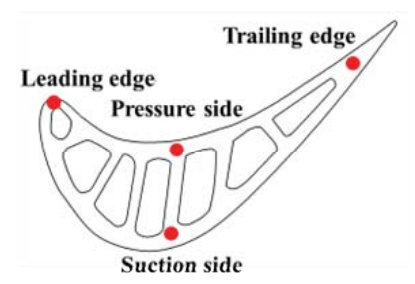

(b)
Fig. 1. Metallographic sectioning method of a serviced turbine blade. (a) Illustration of the cross-sections along a serviced airfoil. (b) Four observed locations in each section of the serviced blade.

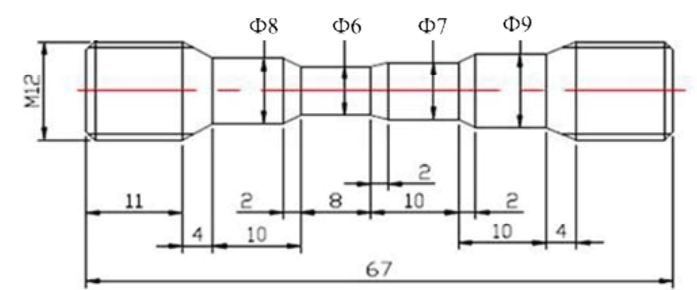

Fig. 2. Sketch of the creep specimen with variable cross-sections for the temperature-stress coupling simulation experiments (units in $\mathrm{mm}$ ).

Table I. Experimental parameters of DZ125 superalloy for temperature-stress coupling simulation experiments.

\begin{tabular}{ccc}
\hline Temperature, ${ }^{\circ} \mathrm{C}$ & Stress, $\mathrm{MPa}$ & Time, $\mathrm{h}$ \\
\hline 900 & $124,158,206,280$ & 300 \\
\hline 950 & $98,124,162,220$ & 300 \\
\hline 1000 & $\begin{array}{c}18,23,29,40, \\
67,84,110,150\end{array}$ & 300 \\
\hline 1050 & $18,23,29,40$ & 300 \\
\hline
\end{tabular}

In every investigated location of serviced turbine blades and samples after service simulation experiments, the microstructure parallel and perpendicular to the (001) orientation were both studied. The metallographic specimens were mechanically polished, and then electrolytically etched in a solution of $12 \%$ phosphate, $40 \%$ nitric acid and $48 \%$ sulfuric acid to observe $\gamma^{\prime}$ precipitates. The microstructural examinations were performed using a ZEISS SUPRA 55 field-emission scanning electron microscope (FE-SEM).

The volume fraction $\left(\mathrm{V}_{f}\right)$ and rafting degree $(\Omega)$ of $\gamma^{\prime}$ precipitates in the dendritic core were used to quantitatively characterize microstructural degradation. The rafting degree was used to evaluate the perfection of the rafting, which was firstly suggested by Underwood et al $[13,14]$. The formula for $\Omega$ is shown below.

$$
\Omega=\frac{\mathrm{P}_{\mathrm{L}}^{\perp}-\mathrm{P}_{\mathrm{L}}^{/ /}}{\mathrm{P}_{\mathrm{L}}^{\perp}+\mathrm{P}_{\mathrm{L}}^{/ /}}
$$

Here, $\mathrm{P}_{\mathrm{L}}$ is the number of intersections per unit length and the terms $/ /$ and $\perp$ denote scans in the directions parallel and perpendicular to the lamella, respectively. The $\mathrm{V}_{f}$ and $\Omega$ values were measured by using Adobe Photoshop and Image-Pro Plus software in the microstructures parallel and perpendicular to the (001) orientation, respectively. In order to obtain statistically significant results, five images were used.

\section{Results}

\section{$\underline{1 . D Z 125}$ alloy and its initial microstructure}

DZ125 alloy was a first generation directionally solidified Nibase superalloy in China. It was developed in Beijing Institute of Aeronautical Materials (BIAM) based on René 125 alloy with the reduction of $\mathrm{Ti}$ and $\mathrm{C}$ content, as well as increasing $\mathrm{Hf}$ content. The measured composition of the studied DZ125 alloy is Ni8.9Cr-10.2Co-7W-2.2Mo-1Ti-3.6Ta-1.4Hf-0.11C-0.016B (wt.\%). Due to the excellent balanced performance of mechanical properties, microstructure stability and castability, DZ125 alloy has been used as high pressure turbine blades in aircraft engines. Its service temperature is generally designed to be below $1000{ }^{\circ} \mathrm{C}$ for rotor blades and below $1050{ }^{\circ} \mathrm{C}$ for stator blades .

The initial microstructure sectioned from an unserviced blade of DZ125 alloy after the standard heat treatment in this study is shown in Fig. 3. It generally consisted of $\gamma$ and $\gamma^{\prime}$ phases in the matrix. In the interdendritic region, the $\gamma+\gamma^{\prime}$ residual eutectics containing irregular and large $\gamma^{\prime}$ phases were observed due to the incomplete solution treatment at $1230{ }^{\circ} \mathrm{C}$, as presented in Fig. 3a, and its volume fraction was about $8 \%$. In addition, two types of carbides, which were identified as $\mathrm{MC}_{(1)}$ and $\mathrm{MC}_{(2)}$, formed after casting and during heat treatment, respectively. Their corresponding higher magnification images in Figs. $3 \mathrm{~b}$ and $3 \mathrm{c}$ indicate that $\mathrm{MC}_{(1)}$ carbides exhibit Chinese script morphology while $\mathrm{MC}_{(2)}$ carbides generally have regular polygon morphology. EDS results show that two types of carbides were enriched in Ta and Hf, respectively. The $\mathrm{MC}_{(1)}$ carbides normally transform to $\mathrm{M}_{6} \mathrm{C}$ or $\mathrm{M}_{23} \mathrm{C}_{6}$ carbides while $\mathrm{MC}_{(2)}$ carbides are very stable during service although they have the same crystal structure [15, 16]. In the dendritic region, however, $\gamma^{\prime}$ precipitates show regular and uniform morphology with the volume fraction of $67 \%$ in Fig. $3 \mathrm{~d}$, while some secondary $\gamma^{\prime}$ precipitates were observed to exist in $\gamma$ channels.

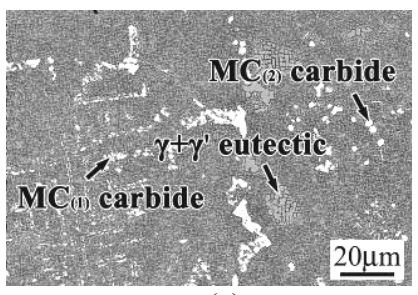

(a)

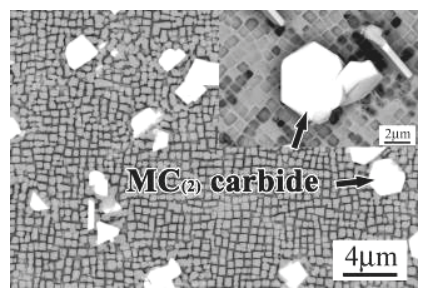

(c)

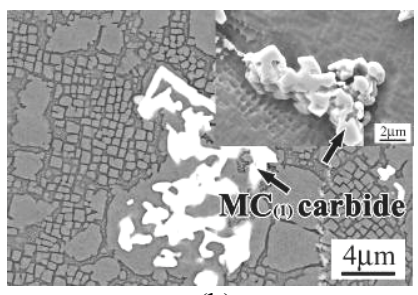

(b)

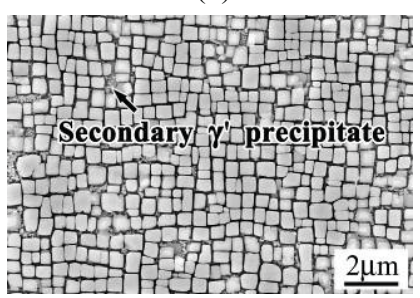

(d)

Fig. 3. Typical microstructure of interdendritic region (a), $\mathrm{MC}_{(1)}$ carbides (b), $\mathrm{MC}_{(2)}$ carbides (c) and dendritic region (d) in an unserviced blade made of DZ125 alloy. 


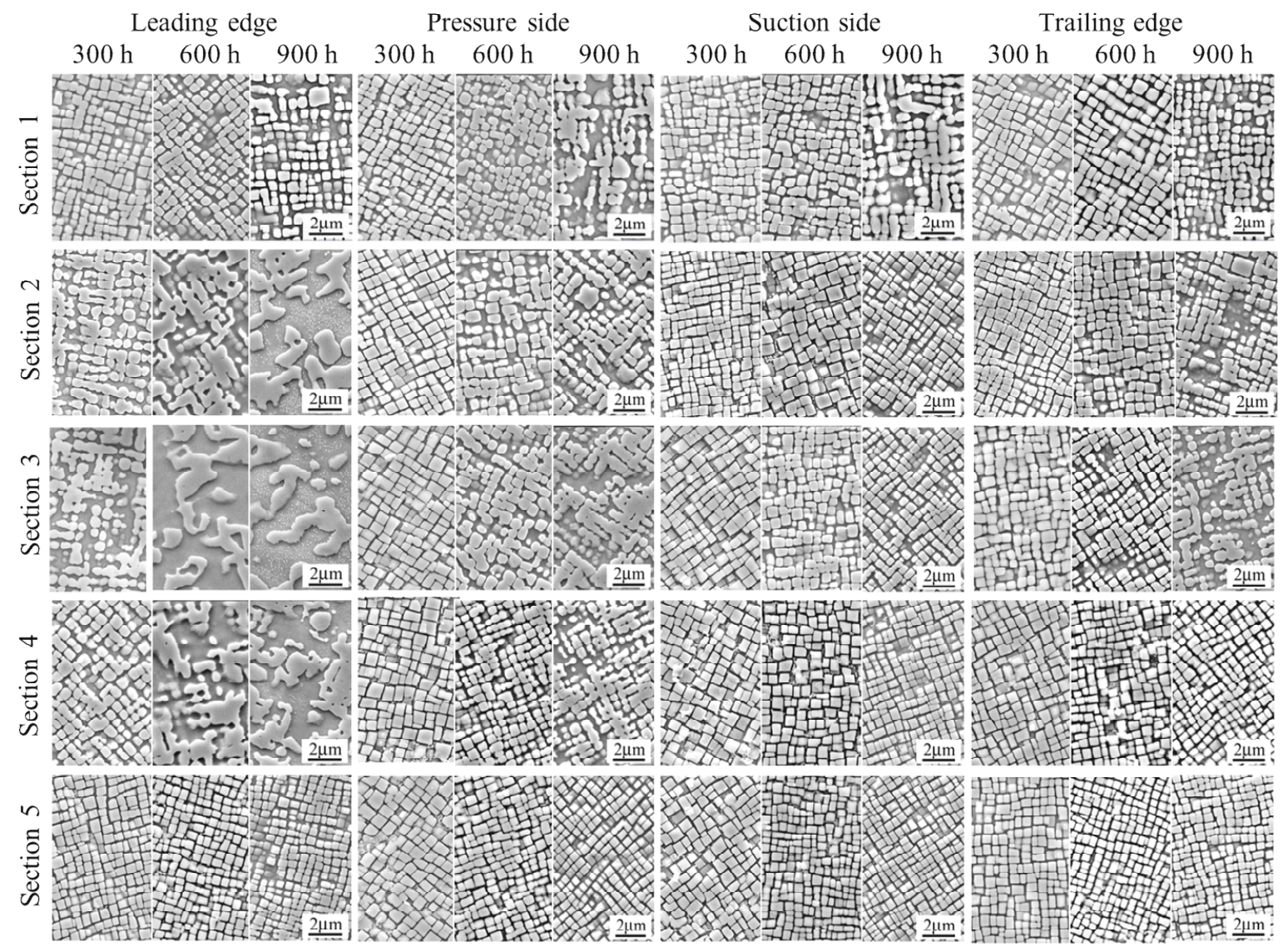

Fig. 4. Typical microstructure in the dendritic region in all investigated locations of three serviced blades parallel to the (001) orientation.

In order to verify the rationality of the service simulation experiments, the initial microstructures of unserviced turbine blades and crystal bars of DZ125 alloy were examined. It is indicated that they have the similar initial microstructure. In addition, it is worth to mention that $\gamma^{\prime}$ precipitates in the dendritic region are the focus in this study due to their significant evolution during service while the evolutions of other phases such as carbides were relatively unconspicuous.

\section{Microstructural degradation of serviced turbine blades}

Fig. 4 shows the microstructural evolution of $\gamma+\gamma^{\prime}$ matrix perpendicular to the (001) orientation in all investigated locations of blades $1(300 \mathrm{~h}), 2(600 \mathrm{~h})$ and $3(900 \mathrm{~h})$. It is clearly indicated that the extent of microstructural degradation varied with locations including the coarsening, coalescence and dissolution of $\gamma^{\prime}$ precipitates, and the adjacent $\gamma^{\prime}$ precipitates connected each other with increasing the serviced time. The most significant changes in $\gamma^{\prime}$ morphology were observed at section 3, especially in the leading edge, for example in L-S3-600 h (Leading edge at section 3 of blade 2) and L-S3-900 h (Leading edge at section 3 of blade 3), the morphology of $\gamma^{\prime}$ precipitates became irregular due to the serious coalescence and dissolution. At section 2 and section 4 , the significant changes of $\gamma^{\prime}$ morphology were also observed in the leading edge, and $\gamma^{\prime}$ precipitates have formed irregular morphology in L-S2-900 h and L-S4-900 h. However, most of $\gamma^{\prime}$ precipitates kept cuboidal morphology at the section 1 and section 5, even in blade $3(900 \mathrm{~h})$.
Fig. 5 shows the microstructural evolution of $\gamma+\gamma^{\prime}$ matrix parallel to the (001) orientation in all investigated locations of blades 1-3. The extent of microstructural degradation also varied with locations including the coarsening, dissolution and rafting. $\gamma^{\prime}$ precipitates gradually formed typical "rafts" with increasing the service time, and further became regular lamellas perpendicular to the applied stress. Similar to Fig. 4, the most significant changes of $\gamma^{\prime}$ morphology also occurred at the leading edge in the middle of the blade. Well aligned rafted $\gamma^{\prime}$ phase appeared at sections 2-4. Particularly, thicker $\gamma^{\prime}$ lamellas were observed and the volume fraction of $\gamma^{\prime}$ precipitates was lower in these locations such as L-S3-600 $\mathrm{h}$ and L-S3-900 $\mathrm{h}$ due to the coarsening and dissolution of $\gamma^{\prime}$ precipitates. However, most of $\gamma^{\prime}$ precipitates retained cuboidal morphology at the section 1 and section 5 . It is indicated that the microstructural degradation behavior of the matrix parallel to the (001) orientation was in well agreement with those that were perpendicular to the (001) orientation through the comparison between Fig. 4 and Fig. 5.

In order to better investigate microstructural degradation of $\gamma^{\prime}$ precipitates, the volume fraction $\left(\mathrm{V}_{f}\right)$ and rafting degree $(\Omega)$ of $\gamma^{\prime}$ precipitates were quantified. The quantitative results of the same locations at three blades, which are P-S3-300 h (Pressure side at section 3 of blade 1), P-S3-600 $\mathrm{h}$ and P-S3-900 h, are shown in Fig. 6. Compared with the corresponding values of the original sample, it is believed that the $V_{f}$ decreased while the $\Omega$ raised significantly during the service of turbine blades. 


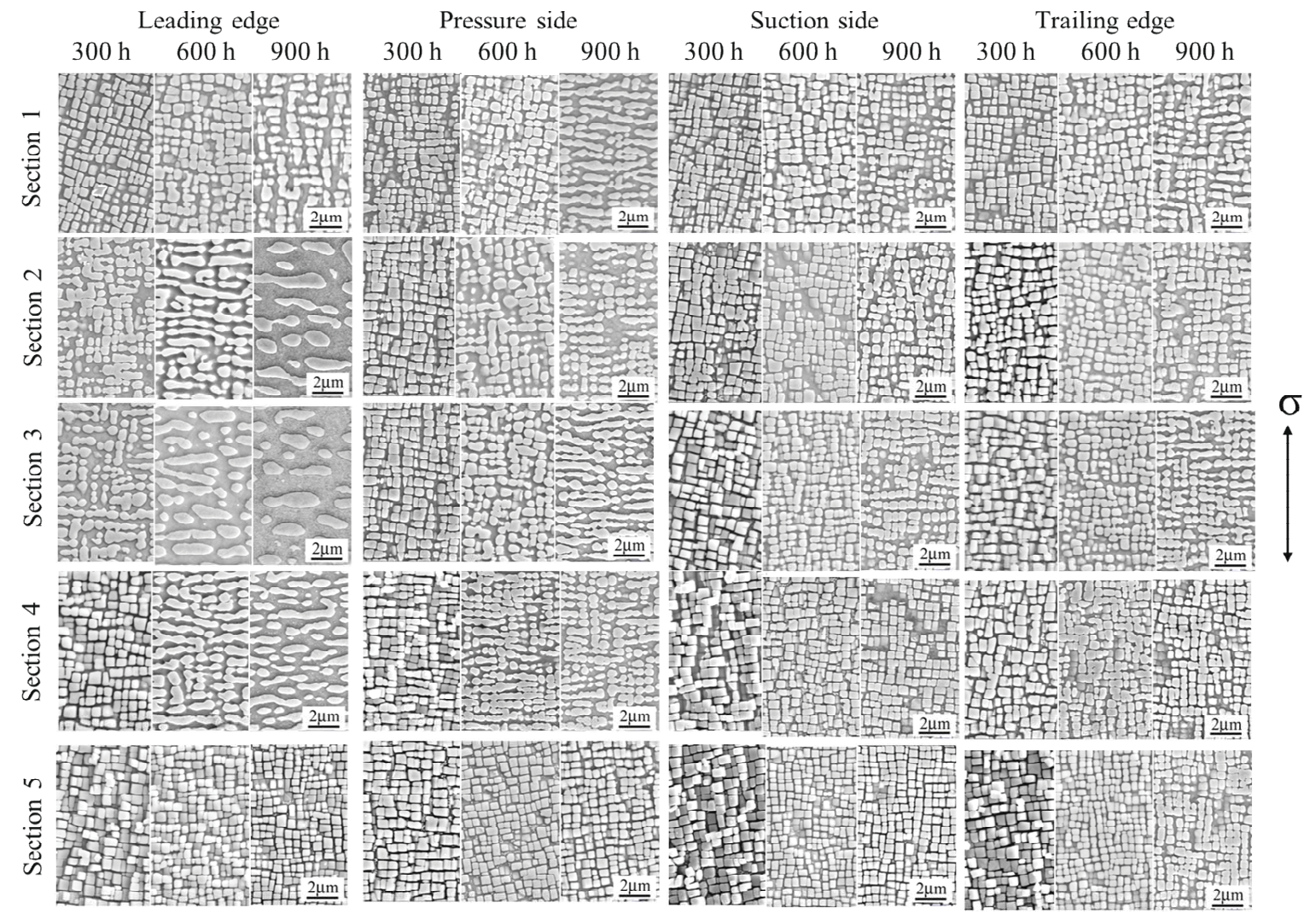

Fig. 5. Typical microstructure in the dendritic region in all investigated locations of three serviced blades perpendicular to the (001)

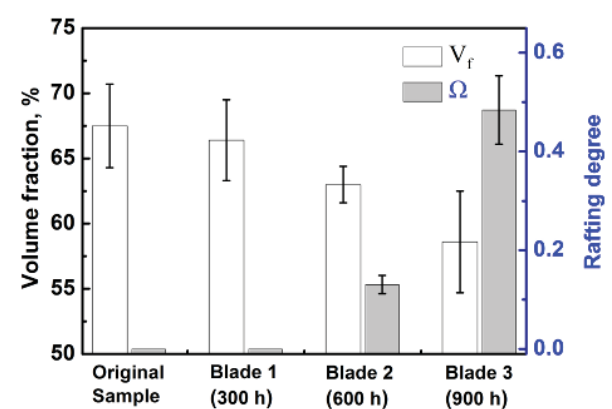

Fig. 6. Microstructural parameters of $\gamma^{\prime}$ volume fraction $\left(\mathrm{V}_{f}\right)$ and rafting degree $(\Omega)$ in the pressure side of section 3 of three serviced blades.

In order to quantitatively investigate the extent of microstructural degradation at different locations in a whole blade, the values of $\mathrm{V}_{f}$ and $\Omega$ were measured in all 20 investigated locations of blade 2 as shown in Fig. 7. The most significant degradation (the minimum $\mathrm{V}_{f}$ and the maximum $\Omega$ ) generally appeared in the middle of the blade (section 3 ), and less degradation appeared at the locations closer to the section 1 or section 5 . The descending order of degradation extent in different locations of each section can also be obtained in Fig. 7, i.e., leading edge, pressure side, trailing edge and suction side. It is obvious that the leading edge in section 3 (middle) of the serviced blades underwent the most serious degradation. Therefore, it can be speculated that the leading edge of the middle of airfoils generally exposed to the strongest coupling effect of service temperature and stress during the service of turbine blades.

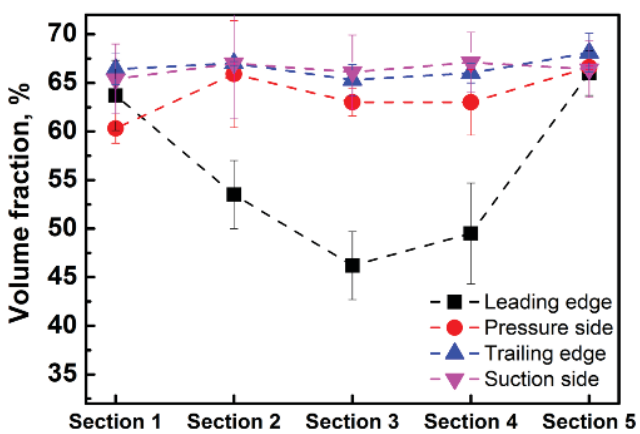

(a)

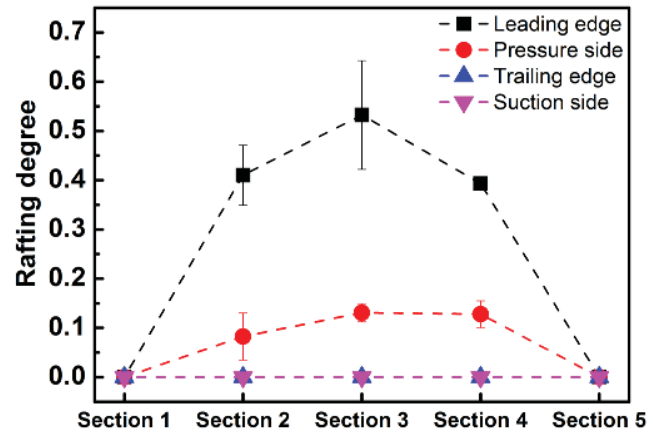

(b)

Fig. 7. Microstructural parameters of $\gamma^{\prime}$ volume fraction (a) and the rafting degree (b) in all twenty investigated locations of blade $2(600 \mathrm{~h})$. 

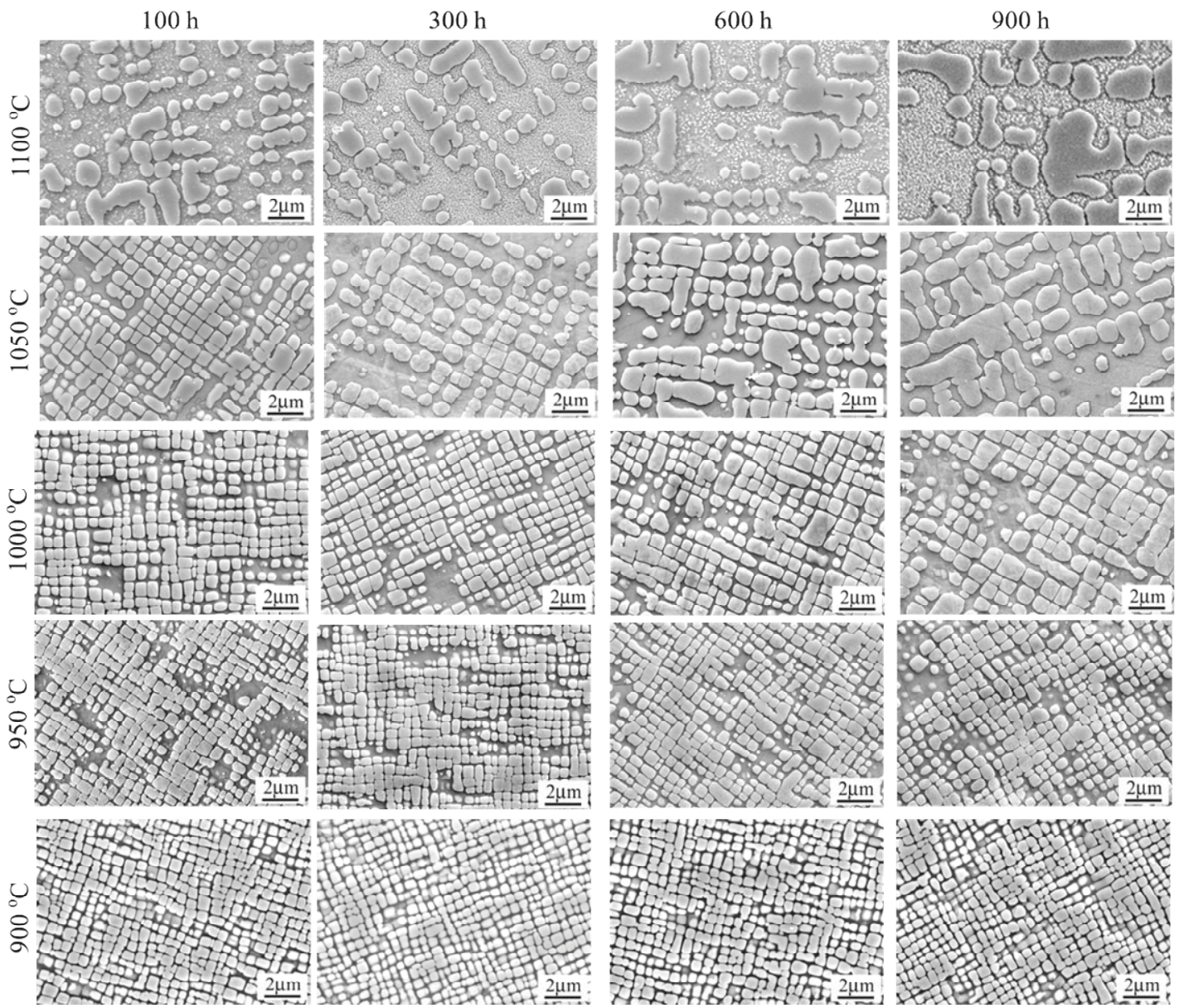

Fig. 8. Typical microstructure of $\gamma+\gamma^{\prime}$ matrix perpendicular to the (001) orientation of DZ125 alloy after thermal exposure in the temperature range of 900 and $1100^{\circ} \mathrm{C}$ between 100 and $900 \mathrm{~h}$.

\section{Service simulation of DZ125 alloy}

In order to investigate the microstructural evolution behavior of turbine blades made of DZ125 during service, the service simulation experiments with and without stress were both conducted on DZ125 alloy. The temperature range was between 900 and $1100{ }^{\circ} \mathrm{C}$, and the range of applied creep stress was between 0 and $280 \mathrm{MPa}$, which are close to the working conditions under the coupling effect of stress and temperature by using computational simulation in serviced turbine blades.

\subsection{Thermal exposure simulation without stress}

Fig. 8 shows the typical microstructure of $\gamma+\gamma^{\prime}$ matrix perpendicular to the (001) orientation of DZ125 alloy after thermal exposure in the temperature range of 900 and $1100{ }^{\circ} \mathrm{C}$ between 100 and $900 \mathrm{~h}$, exhibiting that $\gamma^{\prime}$ precipitates coarsened, significantly dissolved and slightly connected after thermal exposure. It is clearly indicated that the size of $\gamma^{\prime}$ precipitates increased while the $\gamma^{\prime}$ volume fraction decreased with the increasing of exposure time in the temperature range of 1000 and $1100{ }^{\circ} \mathrm{C}$. Meanwhile, higher temperature caused more significant coarsening and dissolution of $\gamma^{\prime}$ precipitates in a certain period of time. For example, it is shown that there were no apparent changes in the size and volume fraction of $\gamma^{\prime}$ precipitates with increasing the exposure time in the temperature range of 900 and $950{ }^{\circ} \mathrm{C}$. However, the obviously coarsening and dissolution of $\gamma^{\prime}$ precipitates occurred in the temperature range of 1000 and $1100{ }^{\circ} \mathrm{C}$, especially in $1100{ }^{\circ} \mathrm{C}, \gamma^{\prime}$ precipitates were significantly dissolved after thermal exposure for only $100 \mathrm{~h}$. The connection between neighboring $\gamma^{\prime}$ precipitates was observed in the temperature range of 1000 and $1100{ }^{\circ} \mathrm{C}$ due to the significant coarsening of $\gamma^{\prime}$ precipitates, but no obvious rafting occurred due to the lack of applied stress.

The quantitative results of $\gamma^{\prime}$ volume fraction $\left(\mathrm{V}_{f}\right)$ in DZ125 alloy after thermal exposure in the temperature range of 900 and $1100{ }^{\circ} \mathrm{C}$ between 100 and $900 \mathrm{~h}$ is presented in Fig. 9, which is consistent with microstructural results (Fig. 8). The $\mathrm{V}_{f}$ values remained above $64 \%$ in the temperature range of 900 and $950{ }^{\circ} \mathrm{C}$ for as long as $900 \mathrm{~h}$. It decreased slowly to about $50 \%$ at $1050{ }^{\circ} \mathrm{C}$ after thermal exposure for $900 \mathrm{~h}$, while it reduced very rapidly to $41 \%$ at $1100{ }^{\circ} \mathrm{C}$ for only $100 \mathrm{~h}$ and slightly decreased to $40 \%$ at $1100{ }^{\circ} \mathrm{C}$ for $900 \mathrm{~h}$. The $\mathrm{V}_{f}$ values decreased more significantly at the early stage and then appeared to be more stable when the thermal exposure time increased in the temperature range of 1000 and $1100{ }^{\circ} \mathrm{C}$. This trend of microstructural evolution is relevant to the thermodynamic state of DZ125 alloy, which will be discussed in detail in Section 4.1. 


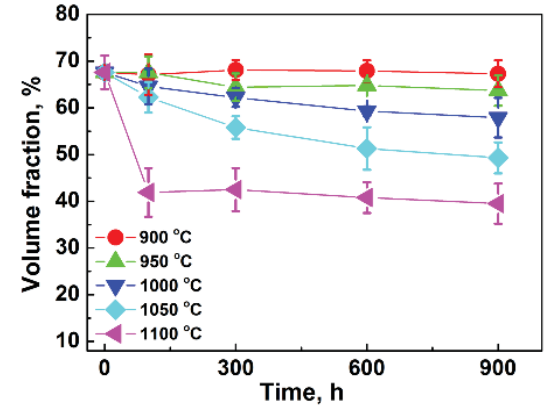

Fig. 9. The volume fraction of $\gamma^{\prime}$ precipitates in DZ125 alloy after thermal exposure in the temperature range of 900 and $1100{ }^{\circ} \mathrm{C}$ between 100 and $900 \mathrm{~h}$.

\section{$\underline{3.2 \text { Temperature-stress coupling simulation }}$}

Fig. 10 shows the typical microstructure of $\gamma+\gamma^{\prime}$ matrix perpendicular to the (001) orientation of DZ125 alloy after the temperature-stress coupling simulation experiments in the temperature range of 900 and $1050{ }^{\circ} \mathrm{C}$ between 0 and $280 \mathrm{MPa}$ for $300 \mathrm{~h}$, exhibiting that $\gamma^{\prime}$ precipitates connected, coarsened, and dissolved significantly at this orientation. In the temperature range of 900 and $1050{ }^{\circ} \mathrm{C}$, the degradation extent of $\gamma^{\prime}$ precipitates increased with increasing the applied creep stress, $\gamma^{\prime}$ precipitates became irregular morphology, which is similar to the microstructure of $\gamma+\gamma^{\prime}$ matrix perpendicular to the (001) orientation in L-S3-600 $\mathrm{h}$ and L-S3-900 $\mathrm{h}$ of serviced blades (Fig. 4). Meanwhile, higher temperature caused more significant coarsening and dissolution of $\gamma^{\prime}$ precipitates when the applied stresses were nearly the same or close. For example, the coarsening and dissolution of $\gamma^{\prime}$ precipitates were not evident in the temperature range of 900 and $950{ }^{\circ} \mathrm{C}$ even though after the temperature-stress coupling simulation at $900{ }^{\circ} \mathrm{C} / 280 \mathrm{MPa}$ and $950{ }^{\circ} \mathrm{C} / 124 \mathrm{MPa}$ for $300 \mathrm{~h}$. But the significant coarsening and dissolution of $\gamma^{\prime}$ precipitates were observed in the temperature range of 1000 and $1050{ }^{\circ} \mathrm{C}$, especially in $1050{ }^{\circ} \mathrm{C}$, the size of $\gamma^{\prime}$ precipitates increased while the $\gamma^{\prime}$ volume fraction decreased significantly even though the applied stress was only $18 \mathrm{MPa}$.

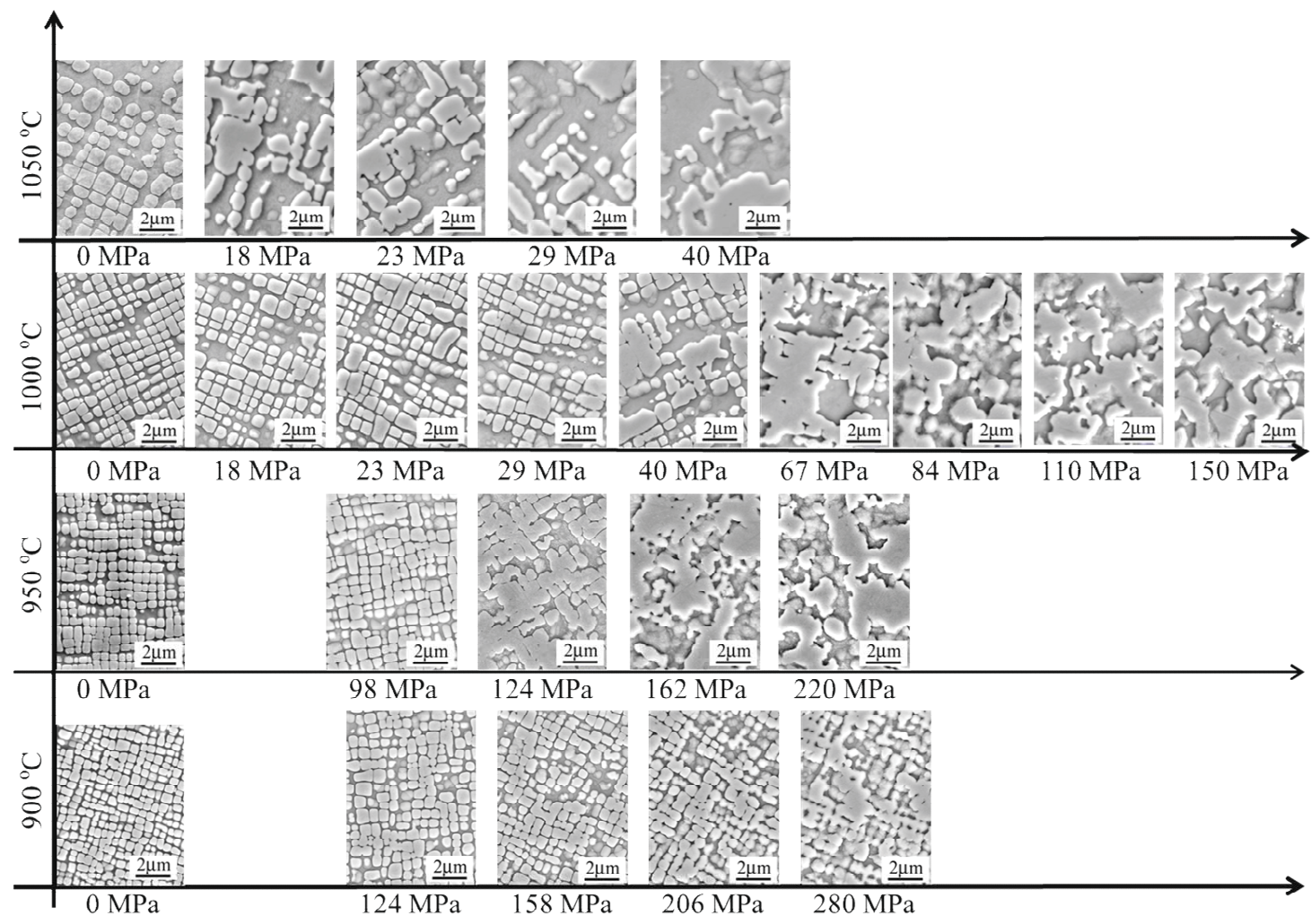

Fig. 10. Typical microstructure of $\gamma+\gamma^{\prime}$ matrix perpendicular to the (001) orientation of DZ125 alloy after temperature-stress coupling simulation experiments in the temperature range of 900 and $1050{ }^{\circ} \mathrm{C}$ between 0 and $280 \mathrm{MPa}$ for $300 \mathrm{~h}$.

Figs. 11 shows the typical microstructure of $\gamma+\gamma^{\prime}$ matrix parallel to the (001) orientation of DZ125 alloy after temperature-stress coupling simulation experiments in the temperature range of 900 and $1050{ }^{\circ} \mathrm{C}$ between 0 and $280 \mathrm{MPa}$ for $300 \mathrm{~h}$, exhibiting that $\gamma^{\prime}$ precipitates coarsened and rafted significantly at this orientation during the temperature-stress coupling simulation experiments. In a certain temperature, the rafting extent was increased with increasing the creep stress, then the well aligned $\gamma^{\prime}$ phase formed when the stress reached a certain value. In addition, higher extent of rafted and thicker $\gamma^{\prime}$ lamellas were observed at $1050{ }^{\circ} \mathrm{C}$ than that in the temperature range of 900 and $1000{ }^{\circ} \mathrm{C}$, even though the applied stress was only $18 \mathrm{MPa}$.

Fig. 12a shows the quantitative results of $\gamma^{\prime}$ volume fraction $\left(\mathrm{V}_{f}\right)$ in DZ125 alloy after temperature-stress coupling simulation experiments for $300 \mathrm{~h}$. It exhibits that $\mathrm{V}_{f}$ values decreased obviously with increasing the temperature. There was no significant influence of the applied stress in the range of 98 and 
$280 \mathrm{MPa}$ on $\mathrm{V}_{f}$ values in the temperature range of 900 and $950{ }^{\circ} \mathrm{C}$. However, the obvious decrease of $\mathrm{V}_{f}$ values occurred in the applied stress range of 18 and $150 \mathrm{MPa}$ as the temperature was increased to $1000{ }^{\circ} \mathrm{C}$ and above, especially at $1050{ }^{\circ} \mathrm{C}$. In comparison with that of thermal exposure without stress at $1050{ }^{\circ} \mathrm{C}$, the $\mathrm{V}_{f}$ values were reduced quickly from $55.8 \%$ to about $50 \%$ under the effect of applied stress in the range of 18 and 23 $\mathrm{MPa}$, then remained stable with the increase of the applied stress. Fig. 12b shows the quantitative results of $\gamma^{\prime}$ rafting degree $(\Omega)$ in DZ125 alloy after temperature-stress coupling simulation experiments for $300 \mathrm{~h}$. In a certain temperature, no rafting was observed $(\Omega=0)$ when there was limited applied stress. The $\Omega$ values became greater than zero when the applied stress exceeded a critical value. Then it gradually increased with the increase of applied stress, and generally tended to be stable. The critical stress values dropped more significantly with increasing the temperature. In addition, the $\Omega$ values increased more rapidly with increasing the applied stress in the temperature range of 1000 and $1050{ }^{\circ} \mathrm{C}$, compared with those in the temperature range of 900 and $950{ }^{\circ} \mathrm{C}$.

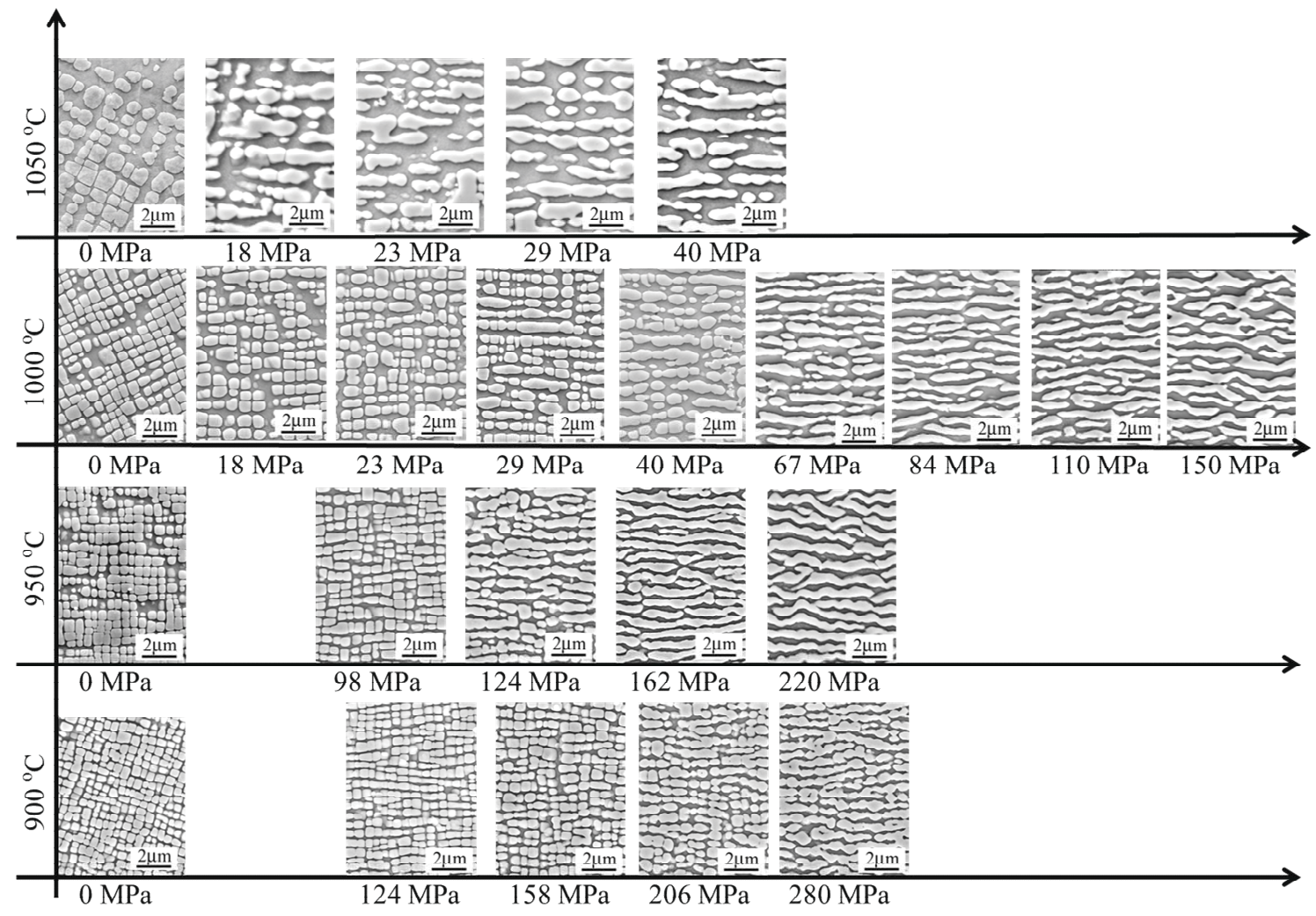

Fig. 11. Typical microstructure of $\gamma+\gamma^{\prime}$ matrix parallel to the (001) orientation of DZ125 alloy after temperature-stress coupling simulation experiments in the temperature range of 900 and $1050{ }^{\circ} \mathrm{C}$ between 0 and $280 \mathrm{MPa}$ for $300 \mathrm{~h}$.

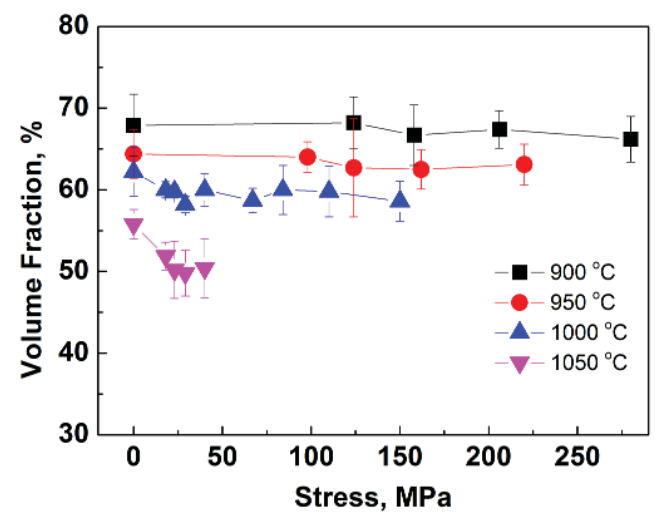

(a)

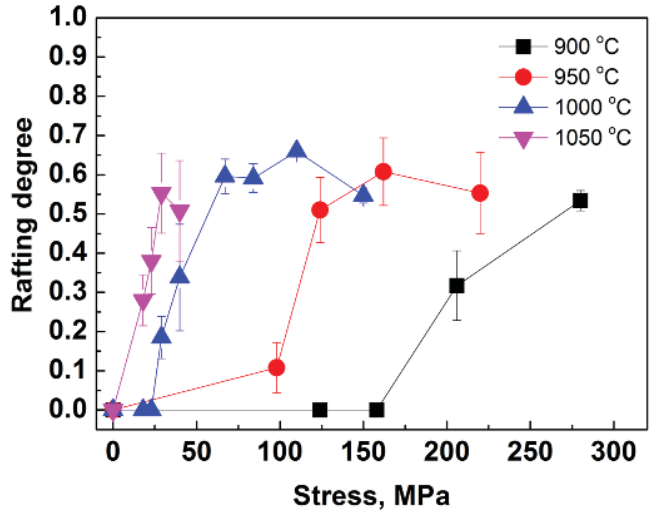

(b)

Fig. 12. Volume fraction (a) and rafting degree (b) of $\gamma^{\prime}$ precipitates in DZ125 alloy after temperature-stress coupling simulation experiments for $300 \mathrm{~h}$. 
Compared with the results of thermal exposure experiment without stress, the rafting behavior of $\gamma^{\prime}$ precipitates became more apparent during temperature-stress coupling simulation experiments. In addition, the more obvious dissolution of $\gamma^{\prime}$ precipitates occurred at the same temperature for the same time under the effect of applied stress when the temperature is above $1000{ }^{\circ} \mathrm{C}$.

\section{Discussion}

$\gamma^{\prime}$ precipitates are the most important strengthening phase in $\mathrm{Ni}$ base superalloys. Mechanical properties of superalloys at high temperature are mainly related to the strengthening by $\gamma^{\prime}$ precipitates $[7,8]$. However, the microstructural degradation of $\gamma^{\prime}$ precipitates is unavoidable due to the effect of temperature and stress during service. In this study, the influence of temperature and stress on $\gamma^{\prime}$ coarsening, rafting and dissolution behaviors were investigated according to the service simulation experiments. Then, the quantitative relationship between temperature, stress and microstructural parameters $\left(\mathrm{V}_{f}\right.$ and $\Omega$ ) were established based on quantitative characterization of $\gamma^{\prime}$ precipitates.

1. Microstructural degradation and the corresponding quantitative characterization

Previous studies suggested that the volume fraction of $\gamma^{\prime}$ precipitates in Ni-base superalloys would decrease after thermal exposure at high temperature [17-20]. For example, the $\gamma^{\prime}$ volume fraction in AM1 and CMSX- $4^{\circledR}$ alloys decreased significantly after thermal exposure, and lower volume fraction was observed at higher temperature [17]. Meanwhile, the applied stress enhanced the dissolution kinetics of $\gamma^{\prime}$ phase at $1200{ }^{\circ} \mathrm{C}$ in CMSX $-4{ }^{\circledR}$ alloy, so the slightly faster $\gamma^{\prime}$ dissolution was observed under applied load conditions [18]. In this study, the significant dissolution and coarsening of $\gamma^{\prime}$ precipitates were observed after thermal exposure without stress (Fig. 8). In the temperature range of 900 and $1100{ }^{\circ} \mathrm{C}$, the $\mathrm{V}_{f}$ values decreased and finally appeared to be a constant value, which was considered to more close to $\gamma^{\prime}$ volume fraction at the equilibrium state of this alloy at the corresponding temperature, especially at higher temperature. In addition, the decreased rate of $\mathrm{V}_{f}$ values varied with the temperature due to higher diffusion rate at higher temperature. It is believed that the temperature was the key factor on the change of $\mathrm{V}_{f}$ values to be more close to the equilibrium.

There has been limited quantitative and systematic research about the effect of applied stress on the dissolution of $\gamma^{\prime}$ precipitates in superalloys. In this study, compared with the thermal exposure simulation under no stress, the applied stress had the significant effect on lowering $\mathrm{V}_{f}$ values when the temperature was in the range of 1000 and $1050{ }^{\circ} \mathrm{C}$ (Fig. 12a). After the temperaturestress coupling simulation for $300 \mathrm{~h}, \mathrm{~V}_{f}$ values decreased quickly to about $57 \%$ at $1000{ }^{\circ} \mathrm{C}$ and about $50 \%$ at $1050{ }^{\circ} \mathrm{C}$, which are consistent with $\mathrm{V}_{f}$ values at the nearly equilibrium state in 1000 and $1050{ }^{\circ} \mathrm{C}$, respectively (Fig. 8). In addition, it is worthy to note that $\mathrm{V}_{f}$ values decreased and then appeared to be stable with the increase of stress. Therefore, it is believed that the applied stress accelerated the $V_{f}$ values reaching the equilibrium state, but had no distinctive effect on the $\mathrm{V}_{f}$ values at the equilibrium state as the constant at the fixed temperature. However, when the thermal exposure temperature was below $1000{ }^{\circ} \mathrm{C}$, the applied stress had little effect on the $\gamma^{\prime}$ volume fraction, which was probably due to lower element diffusion rate at lower temperature.

During high temperature creep deformation, the driving force of $\gamma^{\prime}$ rafting is proportional to the product of the applied stress and the lattice misfit [21-23]. In this study, no rafting was observed after thermal exposure (Fig. 8), while $\gamma^{\prime}$ precipitates presented the obvious rafting in the temperature-stress coupling simulation experiments (Fig. 11). The current study suggests that the $\Omega$ values are able to quantitatively characterize the rafting extent of $\gamma^{\prime}$ precipitates, and it is mainly affected by the applied stress. In addition, it is believed that microstructural evolution during temperature-stress coupling simulation experiments are much closer to those of serviced turbine blades, compared with those of thermal exposure experiments without stress.

\section{Quantitative relationship between microstructure and working conditions}

In order to evaluate the temperature and stress of turbine blades by using the microstructure, the quantitative relationship between them should be established. In this study, the $\mathrm{V}_{f}$ values in the temperature range of 900 and $1050{ }^{\circ} \mathrm{C}$ between 0 and $280 \mathrm{MPa}$ for $300 \mathrm{~h}$ were obtained according to the service simulation experiments. Then the three-dimensional surface map of $\mathrm{V}_{f}$ values as a function of temperature and stress is shown in Fig. 13a. Meanwhile, the corresponding three-dimensional surface map for $\Omega$ values was also drawn, as shown in Fig. 13b. These maps clearly indicate that $\mathrm{V}_{f}$ values decreased gradually with the increase of temperature or stress, which declined from higher values at low temperature and stress to the lower values at high temperature and stress. In addition, temperature had a larger influence on the shape of $\mathrm{V}_{f}$ surface than stress. The $\mathrm{V}_{f}$ values reached the maximum when both temperature and stress were minimum, and reached the minimum when both temperature and stress were the maximum. On the other hand, $\Omega$ values increased from lower values at lower temperature and stress to higher values at higher temperature and stress. The trend in the change of $\Omega$ values suggests that it reached the maximum when both temperature and stress are at the maximum, and reached the minimum when both temperature and stress are at the minimum.

These above results demonstrate that the $\mathrm{V}_{f}$ and $\Omega$ values generally vary in a monotonic way with the temperature and stress, respectively. Then the equivalent average temperature and stress of serviced turbine blades can be evaluated by the quantitative characterization of microstructure, if it is assumed that the temperature and stress keep constant during service. Therefore, for a given $\mathrm{V}_{f}$ and $\Omega$ values, the corresponding service temperature and stress can be evaluated by the three-dimensional surface maps.

\section{Developing a new method to evaluate service temperature and stress of turbine blades}

A new method to evaluate the temperature and stress of serviced turbine blades based on the microstructure is proposed in this study, which is an important step for the assessment method of service-induced damage in turbine blades made of DZ125 superalloy. Generally, this assessment method for this type of 
turbine blades consists of six steps: 1) Conducting macroscopic examination for the serviced turbine blade; 2) Preparing metallographic samples according to the sectioning method in Fig. 1;3) Investigating microstructure (Figs. 4 and 5) in different locations of the serviced blade, and then quantitative characterizing to obtain the corresponding $\mathrm{V}_{\mathrm{f}}$ and $\Omega$ values (Figs. 6 and 7); 4) Conducting the quantitative classification of microstructural degradation extent based on the micrographs (Figs. 4 and 5) and quantitative data (Figs. 6 and 7); 5) Evaluating service temperature and stress of the turbine blade by using the three-dimensional surface maps (Fig. 13). 6) Completing the comprehensive assessment of serviced turbine blade.

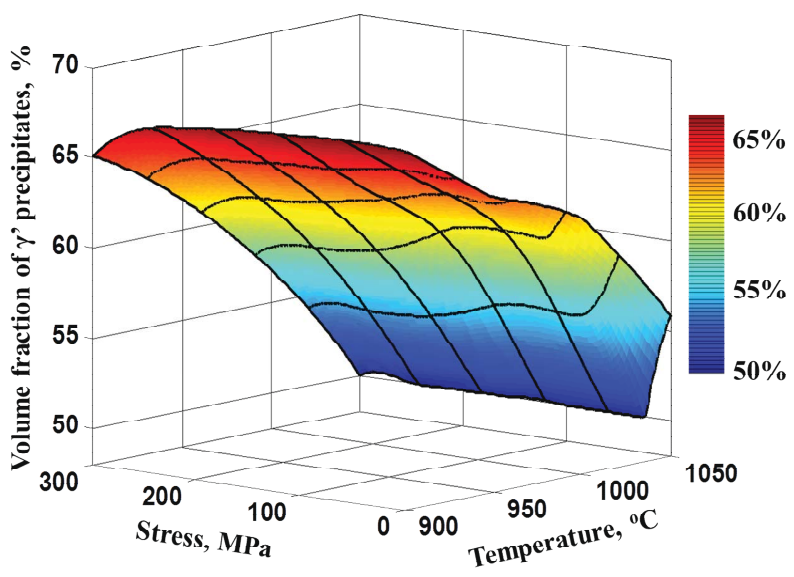

(a)

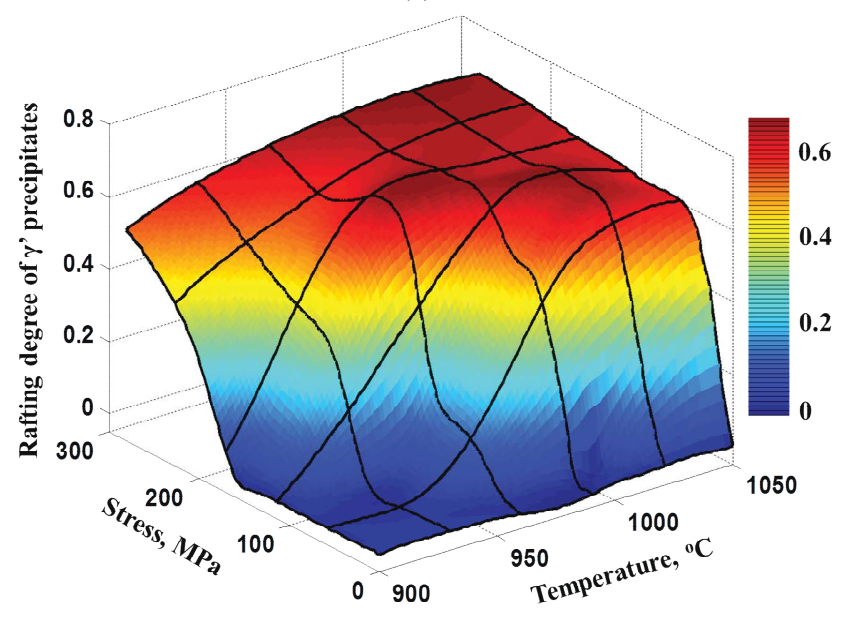

(b)

Fig. 13 Three-dimensional surface maps of volume fraction (a) and rafting degree (b) of $\gamma^{\prime}$ precipitates in DZ125 superalloy under the coupling effect of temperature and stress for $300 \mathrm{~h}$.

In order to better understand the evaluation method of service temperature and stress in step 5, the leading edge in section 3 of serviced blade $1(300 \mathrm{~h})$ is taken as an example to show the evaluation process. After macroscopic examination and metallographic sample preparation, the microstructure of $\gamma+\gamma^{\prime}$ matrix parallel to and perpendicular to the (001) orientation at this location is shown in Fig. 4 and Fig. 5, respectively. The $\mathrm{V}_{f}$ and $\Omega$ values in this location are obtained by the quantitative characterization, i.e. $\mathrm{V}_{f}=57.3 \pm 1.5 \%$ and $\Omega=0.29 \pm 0.02$. Then its service condition can be evaluated according to the threedimensional surface maps of volume fraction and rafting degree of $\gamma^{\prime}$ precipitates in DZ125 superalloy under the coupling effect of temperature and stress for $300 \mathrm{~h}$ (Fig. 13). The service temperature was between 995 and $1037{ }^{\circ} \mathrm{C}$, and the service stress was between 34 and $62 \mathrm{MPa}$. In addition, the distribution of service temperature and stress could have been obtained if more locations of this turbine blade were evaluated.

It is well known that the working conditions of turbine blades vary with the service time and operating conditions of aeroengines. The microstructural damage accumulation of turbine blades after service at different operating conditions has been considered in this study. Therefore, it should be noticed that the evaluation results by using this method are the equivalent average temperature and stress in the whole service time, based on the assumption that the temperature and stress were constant during service. In addition, the improvement of this method to obtain more precise evaluation results is still under research.

\section{Conclusions}

In this study, the influence of temperature and stress on the microstructural degradation of $\gamma^{\prime}$ precipitates, including coarsening, rafting and dissolution behaviors, were investigated in directionally solidified DZ125 superalloy. The quantitative relationship among them was established, then a quantitative assessment method based on microstructure was proposed to evaluate the service temperature, stress and their distributions of the serviced blades. For the turbine blades made of DZ125 alloy, the following conclusions can be drawn:

1. The dissolution extent of $\gamma^{\prime}$ precipitates can be quantitatively characterized by $\gamma^{\prime}$ volume fraction $\left(\mathrm{V}_{f}\right)$, and it is mainly affected by the temperature. The $\mathrm{V}_{f}$ values decreased and then reached the equilibrium state with increasing the time under the effect of temperature without stress. Applied stress accelerated the above process in the temperature range of 1000 and $1050{ }^{\circ} \mathrm{C}$, but had little effect in the temperature range of 900 and $950{ }^{\circ} \mathrm{C}$.

2. The rafting extent of $\gamma^{\prime}$ precipitates can be quantitatively characterized by the rafting degree $(\Omega)$, and it is mainly affected by the stress. In the temperature range of 900 and $1050{ }^{\circ} \mathrm{C}$, rafting occurred only when the applied stress reached a critical value, then the $\Omega$ value increases gradually until it becomes stable with the increase of stress. Meanwhile, a lower critical stress required to initiate the rafting and rapid increase of the $\Omega$ values occurred with increasing the temperature.

3. The $\mathrm{V}_{f}$ and $\Omega$ values varied with locations of the turbine blade and service time, Generally, the $\mathrm{V}_{f}$ values decreased and $\Omega$ values raised gradually in a fixed location during service. According to the microstructure observation and quantitative characterization, the most significant microstructural degradation occurred in the middle of blade, and the microstructure degraded less significantly when the observed location was closer to the tip or the root. The extent of microstructural degradation in the descending order were leading edge, pressure side, trailing edge and suction side in each section. 
4. A new quantitative assessment method of the service conditions, including stress and temperature of serviced turbine blades, is proposed by using the three-dimensional surface maps of temperature-stress- $\mathrm{V}_{f}$ and temperature-stress- $\Omega$, when the $\mathrm{V}_{f}$ and $\Omega$ values are determined at a certain location in the serviced blade.

This assessment method can be applied to turbine blades in aeroengines made of other Ni-base directionally-solidified and single crystal superalloys.

\section{Acknowledgments}

The authors would like to acknowledge useful discussions with W.Y. Yang and F. Tian. The financial support provided by National High Technology Research Program of China (Grant No.: 2012AA03A513) and Science Foundation of Ministry of Education of China (Grant No.: 625010337) is also acknowledged by the authors.

\section{References}

1. Z.X. Wen, et al., "Crystallographic Life Model for Single Crystal Turbine Blade and Validation by the Miniature Specimens Cut from the Turbine Blades," Multidiscipline Modeling in Materials and Structures, 6 (4) (2010), 508-529.

2. D. Dye, M. Anxin and R.C. Reed, "Numerical Modelling of Creep Deformation in a CMSX-4 Single Crystal Superalloy Turbine Blade," Superalloys 2008 Eleventh International Symposium on Superalloys. Warrendale, PA, USA, (2008), 911919.

3. T.J. Carter, "Common Failures in Gas Turbine Blades," Engineering Failure Analysis, 12 (2) (2005), 237-247.

4. A.K. Koul and R. Castillo, "Assessment of Service Induced Microstructural Damage and Its Rejuvenation in Turbine Blades," Metallurgical and Materials Transactions A, 19 (8) (1988), 2049-2066.

5. E. Lvova and D. Norsworthy, "Influence of Service-Induced Microstructural Changes on the Aging Kinetics of Rejuvenated Ni-Based Superalloy Gas Turbine Blades," Journal of Materials Engineering and Performance, 10 (3) (2001), 299-312.

6. X.F. Yuan, et al., "Quantitative Microstructural Evolution and Corresponding Stress Rupture Property of K465 Superalloy," Materials Science and Engineering: A, 651 (2016), 734-744.

7. C.T. Sims, N.S. Stoloff and W.C. Hagel, Superalloys II (New York, NY: Wiley, 1987).

8. M.V. Acharya and G.E. Fuchs, "The Effect of Long-Term Thermal Exposures on the Microstructure and Properties of CMSX-10 Single Crystal Ni-Base Superalloys," Materials Science and Engineering: A, 381 (s 1-2) (2004), 143-153.

9. P.C. Xia, et al., "The Influence of Thermal Exposure on the Microstructure and Stress Rupture Property of DZ951 NickelBase Alloy," Journal of Alloys and Compounds, 443 (1-2) (2007), $125-131$
10. J.M. Aurrecoechea, et al., "Service Temperature Estimation of Turbine Blades Based on Microstructural Observations," Journal of Engineering for Gas Turbines and Power, 113 (2) (1991), 251-259.

11. N. Miura, et al., "Morphology of $\gamma^{\prime}$ Precipitates in Second Stage High Pressure Turbine Blade of Single Crystal NickelBased Superalloy after Serviced," Materials Science Forum, 638642 (2010), 2291-2296.

12. N. Miura, et al., "Morphology of $\gamma^{\prime}$ Precipitates in a First Stage Low Pressure Turbine Blade of a Ni-Based Superalloy after Service and after Following Aging," Journal of ASTM International, 9 (2) (2011), 1-9.

13. E.E. Underwood, Quantitative Stereology (Addison-Wesley, Reading, MA, 1970).

14. M.V. Nathal and R.A. Mackay, "The Stability of Lamellar $\gamma$ $\gamma^{\prime}$ Structures," Materials Science \& Engineering, 85 (87) (1987), 127-138.

15. G. Lvov, V.I. Levit and M.J. Kaufman, "Mechanism of Primary MC Carbide Decomposition in Ni-Base Superalloys," Metallurgical and Materials Transactions A, 35 (6) (2004), 1669-1679.

16. W.R. Sun, et al., "The Eutectic Characteristic of MC-Type Carbide Precipitation in a DS Nickel-Base Superalloy," Materials Science \& Engineering A, 271 (1999), 143-149.

17. B. Roebuck, D. Cox and R. Reed, "The Temperature Dependence of $\gamma^{\prime}$ Volume Fraction in a Ni-Based Single Crystal Superalloy from Resistivity Measurements," Scripta Materialia, 44 (6) (2001), 917-921.

18. R. Giraud, et al., "Strain Effect on the $\gamma^{\prime}$ Dissolution at High Temperatures of a Nickel-Based Single Crystal Superalloy," Metallurgical and Materials Transactions A, 44A (2013), 131146.

19. X.F. Yuan, et al., "Abnormal Stress Rupture Property in K465 Superalloy Caused by Microstructural Degradation at 975 ${ }^{\circ} \mathrm{C} / 225$ MPa," Journal of Alloys and Compounds, 662 (2016), 583-592.

20. J.Y. Tong, et al., "Evaluation of a Serviced Turbine Blade Made of GH4033 Wrought Superalloy," Materials Science and Engineering: A, 618 (2014), 605-613.

21. S. Pierret, et al., "Origin of Localized Rafting in Ni-Based Single Crystal Turbine Blades before Service and Its Influence on the Mechanical Properties," Acta Materialia, 61 (5) (2013), 1478-1488.

22. F.R.N. Nabarro, "Rafting in Superalloys," Metallurgical \& Materials Transactions A, 27A (1996), 513-530.

23. F.R.N. Nabarro, C.M. Cress and P. Kotschy, "The Thermodynamic Driving Force for Rafting in Superalloys," Acta Materialia, 44 (8) (1996), 3189-3198. 